\title{
Metabolic Shift Induced by $\omega-3$ PUFAs and Rapamycin Lead to Cancer Cell Death
}

\author{
Shenglong Zhu ${ }^{a, b}$ Ninghan Fenga,d Guangxiao Lin ${ }^{\mathrm{b}} \quad$ Yuelin Tong \\ Xuan Jiang $^{\mathrm{b}}$ Qin Yang ${ }^{\mathrm{a}, \mathrm{b}}$ Shunhe Wang ${ }^{\mathrm{b}}$ Wei Chen ${ }^{\mathrm{b}}$ Zhao He $\mathrm{He}^{\mathrm{a}, \mathrm{b}, \mathrm{e}, \mathrm{f}}$ \\ Yong Q Chen ${ }^{a, b, c}$
}

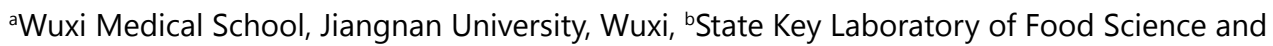
Technology, School of Food Science and Technology, Jiangnan University, Wuxi, China, 'School of Medicine, Wake Forest University, Winston-Salem, North Carolina, USA, 'The Affiliated Wuxi No.2 People's Hospital of Nanjing Medical University, Nanjing, eShandong Provincial Hospital affiliated to Shandong University, Jinan, Shandong, fShandong Key Laboratory of Endocrinology and Lipid Metabolism, Jinan, Shandong, China

\section{Key Words}

Rapamycin • $\omega$-3 PUFAs $•$ Cancer metabolism • Breast cancer

\begin{abstract}
Background/Aims: Rapamycin (Rp), the main mammalian target of rapamycin complex inhibitor, is a promising therapeutic agent for breast cancer. However, metabolic disorders and drug resistance reduce its efficacy. Epidemiological, clinical, and experimental studies have demonstrated that omega-3 polyunsaturated fatty acids ( $\omega-3$ PUFAs) significantly reduce the incidence and mortality of breast cancer and improve metabolic disorders. Methods: Three breast cancer cell lines and immunocompetent and immunodeficient mice were used to evaluate the therapeutic effects of Rp plus $\omega-3$ PUFA treatment. The production of reactive oxygen species (ROS) and glucose uptake were examined by flow cytometry. Metabolic shift was examined by metabonomics, seahorse experiments, and western blot analysis. Results: We found that $\omega-3$ PUFAs and Rp synergistically induced cell cycle arrest and apoptosis in vitro and in vivo, accompanied by autophagy blockage. In addition, Rpinduced hypertriglyceridemia and hypercholesterolemia were completely abolished by $\omega-3$ PUFA supplementation. Moreover, the combined treatment of $\omega-3$ PUFA and Rp significantly inhibited glycolysis and glutamine metabolism. The anti-tumor effects of this combination treatment were dependent on ROS production, which was increased by $\beta$-oxidation and oxidative phosphorylation. Conclusion: Our study revealed that $\omega-3$ PUFA enhanced the antitumor activity of Rp while minimizing its side effects in vitro and in vivo. These results provide novel insights into the mechanisms underlying the potential beneficial effects of Rp combined with $\omega-3$ PUFAs on the prevention of breast cancer.
\end{abstract}

S. Zhu and N. Feng contributed equally to this work.

\begin{tabular}{ll}
\hline Zhao He & Wuxi Medical School, Jiangnan University \\
and Yong Q Chen & Wuxi (China) \\
& E-Mail zhaohe@jiangnan.edu.cn; yqchen@jiangnan.edu.cn
\end{tabular}




\section{Cellular Physiology Cell Physiol Biochem 2018;48:2318-2336 and Biochemistry Published online: 15 August, 2018 \begin{tabular}{l|l} 
DOI: 10.1159/000492648 2018 The Author(s). Published by S. Karger AG, Basel \\
www.karger.com/cpb
\end{tabular} \\ Zhu et al.: $\omega$-3 PUFAs and Rapamycin Co-Treatment Induces Synergistic Antitumor Effect}

\section{Introduction}

Breast cancer is the second leading cause of cancer-related deaths among women, and more than 200, 000 new cases of this condition are diagnosed each year. Although endocrine treatment significantly increases the survival outcomes of patients suffering from breast cancer, it is not effective in patients with triple-negative breast cancer (TNBC) or those who develop endocrine resistance $[1,2]$. Therefore, to overcome toxicity and drug resistance, a combination therapy strategy is often used to treat these patients [3].

Dysregulation of mammalian target of rapamycin (mTOR) signaling occurs in various tumor types, including breast cancer, and has been associated with cancer pathogenesis, disease progression, and treatment resistance [4]. Rapamycin (Rp), the main mTOR complex inhibitor, plays an important role in breast cancer treatment. Studies have shown that Rp and its analogs have significant anti-proliferative and pro-apoptotic effects in breast cancer patients $[4,5]$. However, clinical trials and recent studies have indicated that Rp leads to disease stabilization rather than regression for most cancer types [6]. Furthermore, metabolic disorders and drug resistance have occurred in patients who received Rp administration [79].

The molecular mechanisms by which Rp leads to the development of resistance have not been fully elucidated. However, metabolic disorders are key risk factors for breast cancer, and several clinical investigations have shown a significant association between metabolic syndrome and breast cancer in women $[10,11]$. Therefore, unsatisfactory clinical results may be related to Rp-induced hypertriglyceridemia and hypercholesterolemia.

Statins and fibrates, which are most commonly used to treat metabolic dysfunction, were recently shown to potentiate the anti-tumor activity of $R p[12,13]$. This suggests that administering Rp in combination with lipid-or cholesterol-lowering drugs may be an effective treatment strategy for breast cancer.

Another survival mechanism used by cancer cells after Rp treatment is the upregulation of autophagy, a conserved cellular process that maintains cellular homeostasis [14]. During nutrient deprivation, autophagy allows the cell to survive by reusing intracellular proteins until extracellular nutrients become available [15]. Therefore, the upregulation of autophagy is a common mechanism of resistance to chemotherapy. Although the initial causes of breast cancer onset have yet to be determined, studies have suggested potential links to dietary habits and fat intake [16]. Dietary omega- 3 polyunsaturated fatty acids $(\omega-3$ PUFAs) mainly consist of docosahexaenoic acid (DHA; 22:6n-3) and eicosapentaenoic acid (EPA; 20:5n-3). Epidemiological, clinical, and experimental studies have demonstrated that $\omega-3$ PUFAs significantly reduce the incidence and mortality of breast cancer and improve metabolic disorders $[17,18]$. Furthermore, long-term treatment with $\omega$-3 PUFAs reportedly cause blockade of autophagic flux [19], suggesting that as a fuel protein or signal molecule addition, they may improve Rp-induced autophagy activation.

The goal of this study was to determine whether supplementing Rp with $\omega-3$ PUFAs enhances its anti-tumor activity, reduces drug resistance, and improves metabolic disorders during breast cancer treatment.

\section{Materials and Methods}

Ethics approval and consent to participate

Ethics approval and consent to participate in the study were obtained from the Animal Research Ethics Committee of Jiangnan University.

Consent for publication

Consent to publish was obtained from the participants. 


\section{Cellular Physiology Cell Physiol Biochem 2018;48:2318-2336 and Biochemistry Published online: 15 August, 2018 \begin{tabular}{l|l} 
DOI: 10.1159/000492648 2018 The Author(s). Published by S. Karger AG, Basel \\
www.karger.com/cpb
\end{tabular} Zhu et al.: $\omega$-3 PUFAs and Rapamycin Co-Treatment Induces Synergistic Antitumor Effect}

Availability of data and materials

Please contact the author for data requests.

\section{Drugs and reagents}

3-Methyladenine (3-MA), Rp, chloroquine (CQ), Oligomycin A, 2-Deoxy-D-gluocose (2-DG), CB-839, etomoxir, and N-benzyloxycarbonyl-Val-Ala-Asp-fluoromethylketone (Z-VAD-FMK) were purchased from MedChem Express (Shanghai, China). DHA and EPA were purchased from Nuchek (Waterville, MA). Insulin was purchased from Sigma-Aldrich (St. Louis, MO).

\section{Cell culture}

The breast cancer cell lines MCF-7, SKBR-3, and MDA-MB-231 (Institute of Cell Biology, Shanghai, China) were maintained in Dulbecco's Modified Eagle's Medium supplemented with $10 \%$ fetal bovine serum (Gibco, Gaithersburg, MD), $100 \mu \mathrm{g} / \mathrm{mL}$ penicillin, and $100 \mu \mathrm{g} / \mathrm{mL}$ streptomycin in a humidified atmosphere containing $5 \% \mathrm{CO}_{2}$ at $37^{\circ} \mathrm{C}$. Prior to treatment, cells were grown to $60-70 \%$ confluence and exposed to serum-free medium for $24 \mathrm{~h}$.

\section{Cell counting and proliferation assay}

Cells were cultured in 6-well plates and incubated for $24 \mathrm{~h}$. When grown to $60-70 \%$ confluence, cells were treated with various concentrations of $\omega$-3 PUFAs $(20,40$, or $80 \mu \mathrm{M})$ and/or with Rp $(1,10$, or $20 \mu \mathrm{M})$ and incubated for $48 \mathrm{~h}$. The cells were digested with trypsin and counted.

\section{Flow cytometry analysis of cell cycle and apoptosis}

The cell cycle was determined with propidium iodide (PI) staining; PI was purchased from SigmaAldrich. The Annexin V-fluorescein (FITC)/PI Apoptosis Detection Kit was purchased from BD Pharmingen (San Diego, CA). Cells were treated for $24 \mathrm{~h}$, collected, fixed in $70 \%$ ethanol, and stored at $4^{\circ} \mathrm{C}$ prior to cell cycle analysis. After the removal of ethanol by centrifugation, cells were washed twice with phosphatebuffered saline (PBS) and stained with a solution containing $100 \mu \mathrm{g} / \mathrm{mL}$ RNase A, $0.2 \%$ Triton X-100, and $50 \mu \mathrm{g} / \mathrm{mL}$ PI. For analysis of apoptosis, following treatment for $48 \mathrm{~h}$, aliquots containing $1 \times 10^{5}$ cells in $100 \mu \mathrm{L}$ buffer were stained with $5 \mu \mathrm{L}$ PI solution and $5 \mu \mathrm{L}$ FITC-conjugated Annexin V for 15 min at $37^{\circ} \mathrm{C}$. After staining, $400 \mu \mathrm{L}$ binding buffer was added to the cells, and the samples were stored on ice until data acquisition. All analyses were performed with the Life Attune NxT Flow Cytometer (Life Technologies, Carlsbad, CA) with Novo Express Software (ACEA Biosciences Inc., Hangzhou, China).

\section{Small interfering RNA transfection and western blot analysis}

Carnitine palmitoyltransferase 1 (CPT1) and non-targeting control small interfering RNA (siRNA) oligonucleotides were obtained from GenePharma Co., Ltd. (Suzhou, China). Cells were transfected with the appropriate siRNA using jetPRIME reagent (Polyplus, Illkirch-Graffenstaden, France) according to the manufacturer's protocol. Cells were harvested, washed twice with ice-cold PBS, and subjected to western blot analysis as previously described [20]. The following antibodies were used: microtubule-associated protein 1 light chain 3 beta (LC3B, \#L7543; Sigma), mTOR (\#A2445; ABclonal Technology, Woburn, MA, USA), phosphorylated mTOR (p-mTOR, serine 2448 [S2448], \#AP0094; ABclonal), Beclin-1 (\#A7353; ABclonal), UV radiation resistance associated gene (UVRAG, \#A8462; ABclonal), p-p70S6 kinase (threonine 389 [T389], \#9234; Cell Signaling Technology, Danvers, MA), Glycolysis Antibody Sampler Kit ( \#8337; Cell Signaling Technology), peroxisome proliferator-activated receptor alpha (PPAR $\alpha$; Santa Cruz Biotechnology, Dallas, TX), $\beta$-actin (N21, \#sc-130656; Santa Cruz Biotechnology), Ki67 (\#ab15580; Abcam, Cambridge, UK), and total OXPHOS antibody cocktail (\#ab110143; Abcam). Goat anti-rabbit secondary antibody (A00098) was purchased from GeneScript Biotech Corporation (Piscataway Township, NJ).

\section{Measurement of reactive oxygen species generation}

Cellular reactive oxygen species (ROS) levels were measured by flow cytometry as previously described $[20,21]$. Briefly, $5 \times 10^{5}$ cells were cultured in 6-well plates, incubated for $24 \mathrm{~h}$, and allowed to attach overnight. Then, cells were pre-stained with $10 \mu \mathrm{M}$ dichlorodihydrofluorescein diacetate (DCFH-DA) for 30 min and exposed to either Rp, $\omega$-3 PUFAs, or a combination of both drugs for the indicated time periods. 


\section{Cellular Physiology Cell Physiol Biochem 2018;48:2318-2336

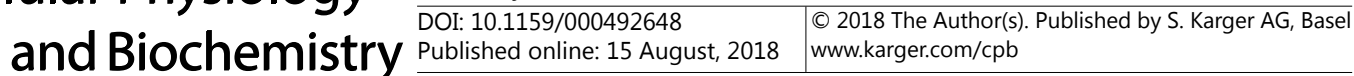 \\ Zhu et al.: $\omega$-3 PUFAs and Rapamycin Co-Treatment Induces Synergistic Antitumor Effect}

DCFH-DA is oxidized to dichlorodihydrofluorescein (DCF) in the presence of ROS, so DCF fluorescence was analyzed by FACS Calibur flow cytometry.

\section{In vitro oxygen consumption and glycolysis}

The in vitro oxygen consumption rate (OCR) and extracellular acidification rate (ECAR) in MDA-MB-231 cells were determined using the Seahorse XF24 Extracellular Flux Analyzer as previously described [22]. Briefly, 20, 000 cells were seeded in the XFE24 microplate with complete media. Then, $6 \mathrm{~h}$ after seeding, cells were treated with the indicated concentrations of $\omega$-3 PUFAs $(40 \mu \mathrm{M})$ and/or Rp $(10 \mu \mathrm{M})$ and incubated for 6 h. After incubation, the complete medium was removed and replaced with $150 \mu \mathrm{L}$ bicarbonate-free medium in a $\mathrm{CO}_{2}$-free incubator for $1 \mathrm{~h}$ before analysis. The basal mitochondrial respiration (OCR) was measured, and the ECAR was measured as a surrogate for lactate production and glycolysis. Data were normalized by cell number per well and quantified using Operetta (image-based quantification).

\section{Metabolic assays}

Malondialdehyde (MDA), lactate production, and ATP levels were measured using assay kits from BioVision (San Francisco, CA). Metabolites were determined by gas chromatography-mass spectrometry (GC-MS). The cells are quenched in $60 \%$ methanol supplemented with $0.85 \%$ (wt/vol) ammonium bicarbonate at $-40^{\circ} \mathrm{C}$. Then, metabolites were extracted from the quenched cells by two $100 \%$ methanol extractions followed by a single water extraction. The metabolite samples generated using this protocol were amenable to analysis by GC-MS as previously described [23].

\section{Xenograft breast cancer model and treatment}

The animal protocol was approved by the Jiangnan University Animal Care and Use Committee (Jiangsu Sheng, China). Female nude mice (purchased from Slaccas, Shanghai, China) aged 4 to 5 weeks received injections of $4 \times 10^{5}$ breast cancer cells (MDA-MB-231). Two weeks later, mice with similar tumor masses were randomized into four treatment groups: control (vehicle), EPA (3 g in $100 \mathrm{~g}$ diet), Rp (5 mg in $100 \mathrm{~g}$ diet), and EPA and Rp combination treatment. The mice were treated for 2 weeks. Tumor sizes were measured twice a week. The tumor volumes were calculated using the following formula: volume $=1 / 2 \times$ length $\times$ width $^{2}$. The mice were sacrificed after the treatment period. Blood was collected from the retroorbital sinus of each non-anesthetized mouse to measure biochemical indexes including serum levels of triglyceride (TG), total cholesterol (TC), high-density lipoprotein cholesterol (HDL-C), lowdensity lipoprotein cholesterol (LDL-C), and MDA. Analyses were conducted using the BS-480 Clinical Chemistry Analyzer (Mindray Medical International Ltd., Shenzhen, China) according to the manufacturer's instructions. Paraformaldehyde-fixed tumor tissues were embedded in paraffin and sectioned $(4 \mathrm{~mm})$. The sections were treated with $0.3 \%$ hydrogen peroxide/methanol and incubated with monoclonal antibodies, followed by incubation with Histostain-Plus IHC Kit (Thermo Fisher Scientific, Waltham, MA, USA) reagents according to the manufacturer's instructions.

\section{MMTV-PyVT mammary tumor model}

The MMTV-PyVT (polyoma virus middle $\mathrm{T}$ oncogene) mammary tumorigenesis mouse model was obtained from the Model Animal Research Center of Nanjing University (Jiangsu Sheng, China). Female MMTV-PyVT mice were used in this study. Mice aged 6 weeks with similar body weight were randomized into five treatment groups: control (vehicle), EPA (3 g in $100 \mathrm{~g}$ diet), Rp (5 mg in $100 \mathrm{~g}$ diet), EPA+Rp, and $\mathrm{RP}+\mathrm{EPA}+\mathrm{N}$-acetyl-L-cysteine (NAC). The mice were treated for 4 weeks. Body weight was measured weekly. All tumors were excised and weighed. The mice were sacrificed after the treatment period. Blood was collected from the retroorbital sinus of each non-anesthetized mouse to measure biochemical indexes including serum levels of TG, TC, HDL-C, LDL-C, and MDA.

\section{Statistical analysis}

All animal experiments were approved by the Ethics Committee of Jiangnan University. Data were reported as the mean \pm standard error of the mean (SEM). Statistical significance was determined by oneway analysis of variance followed by the Dunnett's test for multiple comparisons. Statistical analyses were performed using SPSS software (version 20.0; SPSS Inc., Chicago, IL). P values less than 0.05 were considered statistically significant. For western blot analyses, one representative set of data is shown. 


\section{Cellular Physiology Cell Physiol Biochem 2018;48:2318-2336 and Biochemistry Published online: 15 August, 2018 \begin{tabular}{l|l} 
DOI: 10.1159/000492648 & $\begin{array}{l}\text { (c) } 2018 \text { The Author(s). Published by S. Karger AG, Basel } \\
\text { www.karger.com/cpb }\end{array}$
\end{tabular} Zhu et al.: $\omega$-3 PUFAs and Rapamycin Co-Treatment Induces Synergistic Antitumor Effect}

\section{Results}

\section{$\omega-3$ PUFA and Rp treatment induce cell cycle arrest}

Based on the expression of estrogen receptor alpha (ER $\alpha)$ and human epithelial growth receptor 2 (HER2) amplification, breast cancer is often classified into three subtypes: ER $\alpha$ positive $\left(E R \alpha^{+}\right)$, HER2-positive (HER2 ${ }^{+}$), and TNBC [24]. Three human breast carcinoma cell lines (MCF-7, SKBR-3, and MDA-MB-231) were used to determine the combined effects of Rp and $\omega-3$ PUFAs for treating various subtypes of breast cancer. Cells were treated with Rp, $\omega-3$ PUFAs, or Rp+ $\omega-3$ PUFAs for up to 3 days. As shown in Fig. 1A, EPA and DHA had no significant inhibitory effects at concentrations below $40 \mu \mathrm{M}$. Rp exhibited no significant cytotoxicity in the three cell lines at concentrations below $10 \mu \mathrm{M}$. Based on these results, $40 \mu \mathrm{M} \omega-3$ PUFAs and $10 \mu \mathrm{M}$ Rp were used in the combination treatment. The combination treatment significantly reduced the cell count in all of the breast cancer cell lines. Maximal inhibition of 78\% compared with untreated cells was achieved by day 3 in the combined $\mathrm{Rp}$ and DHA or EPA treatment groups (Fig. 1B). Overall, these results demonstrated that $\omega-3$ PUFAs and Rp synergistically inhibited the cell growth of not only $\mathrm{ER}^{+}$and $\mathrm{HER}^{+}$but also TNBC cells. To investigate whether cell cycle arrest causes the inhibition of cell growth, we used flow cytometry to analyze cell cycle progression following treatment with single $\omega-3$ PUFAs, Rp, and a combination of $\omega-3$ PUFA+Rp. Compared with untreated cells, in the treated cells, each drug individually caused no significant change in cell cycle distribution. However, the combination of $\omega-3$ PUFA+Rp induced the significant accumulation of cells in the G0/G1 phase coupled with a marked reduction of cells in the S and G2/M phases of the cell cycle of SKBR-3 and TNBC cells. In MCF-7 cells, the significant accumulation of cells in the G2/M phase and marked reduction of cells in the S and G0/G1 phases of the cell cycle were observed (Fig. 1C). To further investigate the mechanisms underlying combination treatment-induced cell cycle arrest, we examined the expression of p21, p27, and cyclin D1, which plays important roles in the regulation of cell cycle arrest [25]. Western blotting results showed that cyclin D1 expression in all three subtypes of breast cancer cells was not dramatically altered by $\omega-3$ PUFAs, Rp, and $\omega-3$ PUFA+Rp (Fig. 1D). However, compared to single reagents, the combination of $\omega-3$ PUFAs and Rp markedly decreased the expression of p21 and p27 in all three breast cancer cell lines, showing the synergistic suppressive effects on p21 and p27 expression (Fig. 1D).

\section{$\omega$-3 PUFA and Rp synergistically promote cell apoptosis}

In addition to cell cycle arrest, cell apoptosis can cause the inhibition of cell growth. Hence, we investigated whether apoptosis was induced by $\omega-3$ PUFAs, Rp, and $\omega-3$ PUFA+Rp. By flow cytometry analysis of Annexin V/PI-stained cells, we found that the population of apoptotic cells in all three cell lines was remarkably elevated following incubation with $\omega-3$ PUFA+Rp combined treatment compared with single $\omega-3$ PUFA or Rp treatment, indicating that $\omega-3$ PUFAs and $\mathrm{Rp}$ had synergistic effects on the induction of cell apoptosis in all three cell lines (Fig. 2A, B). As is well known, cleaved-poly(ADP-ribose) polymerase (PARP) and the reduction of $\mathrm{Bcl}-2$ act as key indicators of apoptosis [26]. To investigate whether the cleavage product of PARP and the expression of Bcl-2 could be altered by single or combination treatment, we examined the protein level of both cleaved PARP and Bcl-2 in cells following $\omega-3$ PUFA and Rp treatment and $\omega$-3 PUFA+Rp combination treatment. Western blot analysis revealed that the combined treatment of $\omega-3$ PUFAs and Rp significantly increased the level of cleaved PARP and markedly decreased the Bcl-2 protein level compared with single drug treatment, which showed the synergistic effects of $\omega-3$ PUFA+Rp on the expression of both cleaved PARP and Bcl-2 (Fig. 2C). Furthermore, Z-VAD-FMK, which is generally used as an apoptosis inhibitor [27], significantly prevented the combination of $\omega-3$ PUFA+Rp-induced cell death in all breast cancer cell lines (Fig. 2D). These results suggest that the combination of $\omega-3$ PUFA+Rp synergistically induce breast cancer cell apoptosis. 


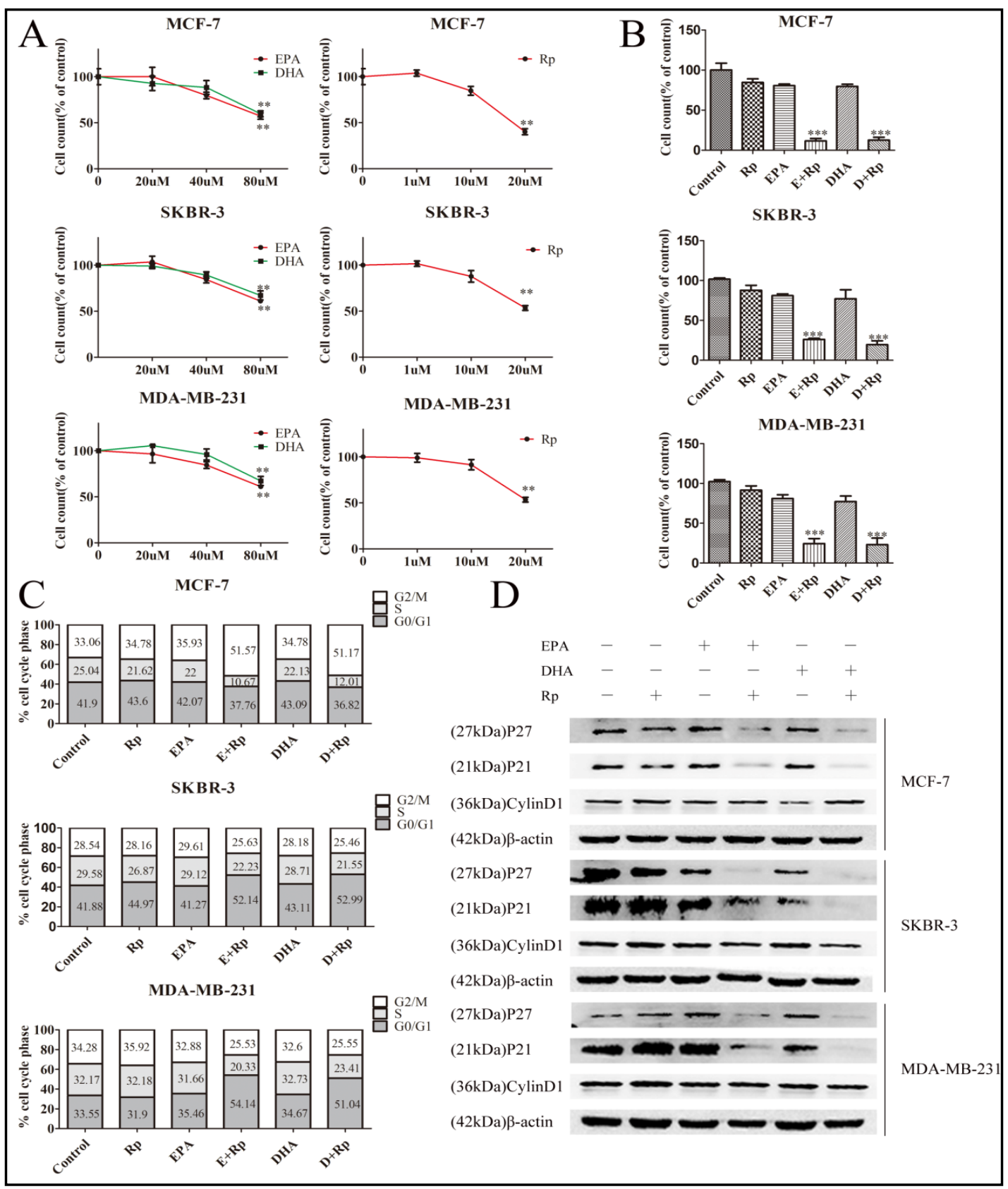

Fig. 1. Cell growth and cell cycle. MCF7, SKBR-3, and MDA-MB-231 breast cancer cells were treated with different concentrations of $\omega-3$ PUFAs and Rp for $72 \mathrm{~h}$, followed by the cell counting assay (A). Inhibitory effects of the combined treatment of $40 \mu \mathrm{M} \omega-3$ PUFAs and $10 \mu \mathrm{M}$ Rp on MCF-7 SKBR-3 and MDA-MB-231 cells, as determined by the cell counting assay (B). The cell cycle was analyzed by flow cytometry and the percentage of total cell population in the different phases of the cell cycle was determined (C). Expression of p21, p27, and cyclin D1 protein (D). Values represent the mean $\pm \operatorname{SEM}(\mathrm{n}=3){ }^{*} \mathrm{P}<0.05 ;{ }^{* *} \mathrm{P}<0.01$; $^{* * *} \mathrm{P}<0.001$.

\section{Combination treatment of Rp and $\omega-3$ PUFAs blocks autophagic flux}

Numerous reports have been published on the relationship between autophagy and cancer progression and initiation. In response to environmental stresses (e.g., nutrient starvation, hypoxia, infections), autophagy is upregulated to provide the energy supply needed for cell survival and repair [28], and recent studies have shown that the induction of autophagy facilitates cancer cell resistance to Rp-induced apoptosis [29]. Previous studies

\section{KARGER}




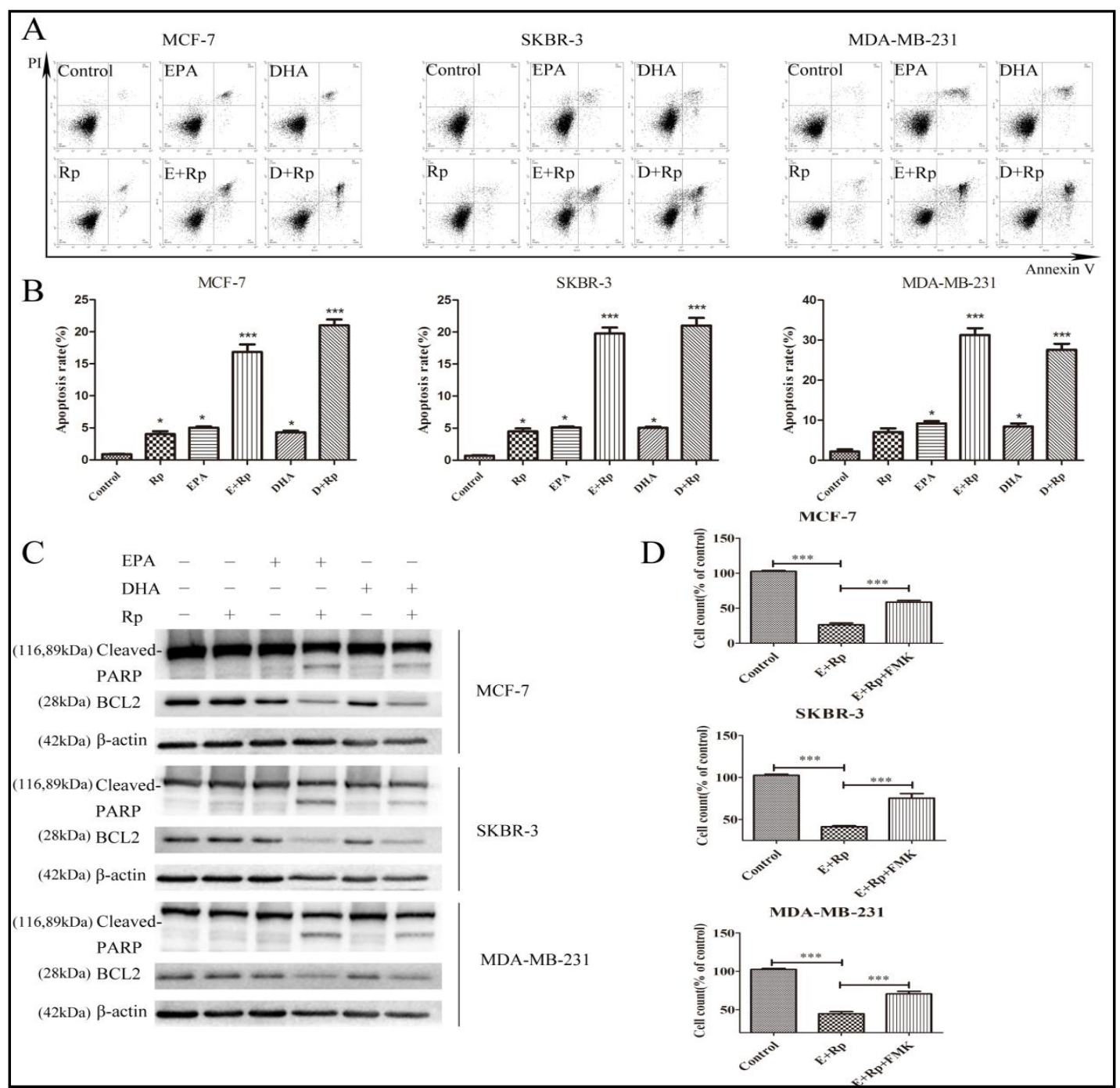

Fig. 2. Cell apoptosis. MCF7, SKBR-3, and MDA-MB-231 cells were treated with $40 \mu \mathrm{M} \omega-3$ PUFAs and 10 $\mu \mathrm{M}$ Rp. Cell apoptosis was analyzed by flow cytometry with PI and Annexin V-FITC staining (A) and the percentage of apoptotic cells at two different stages was assessed (B). PARP and Bcl-2 protein levels after $48 \mathrm{~h}$ of treatment (C). Cells were pretreated with $10 \mu \mathrm{M}$ Z-VAD-FMK for $1 \mathrm{~h}$ and then exposed to $40 \mu \mathrm{M} \omega-3$ PUFAs and $10 \mu \mathrm{M} \mathrm{Rp}$ for $48 \mathrm{~h}$, followed by the cell counting assay (D). Values represent the mean $\pm \mathrm{SEM}(\mathrm{n}=$ 3); ${ }^{*} \mathrm{P}<0.05 ;{ }^{* *} \mathrm{P}<0.01 ;{ }^{* * *} \mathrm{P}<0.001$.

have found that long-term treatment with $\omega$-3 PUFAs causes the blockade of autophagic flux $[19,30]$. Thus, we determined whether autophagy plays a key role in the synergistic effects caused by $\omega-3$ PUFA+Rp combination treatment. Neither Rp nor $\omega-3$ PUFAs had significant effects on LC3II expression (an autophagosome biomarker) in the breast cancer cell lines (Fig. 3A). However, the combination of Rp and $\omega-3$ PUFAs caused a significant increase in LC3II/ $\beta$-actin in all of the breast cancer cell lines tested coupled with a marked decrease in formation of the autophagy elongation complex (ATG5-12) complex, which is a key step in autophagosome biogenesis [31], suggesting that combination treatment may inhibit autophagy initiation and the fusion of autophagosomes with lysosomes. Autophagy is a highly dynamic process in mammalian cells. Therefore, monitoring autophagic flux is necessary for determining the rate of autophagy $[32,33]$. Autophagic flux was measured by comparing LC3II/ $\beta$-actin levels in the cases of combination treatment with or without CQ (by increasing lysosomal pH) and long-lived protein p62 degradation. These two general methods for

\section{KARGER}




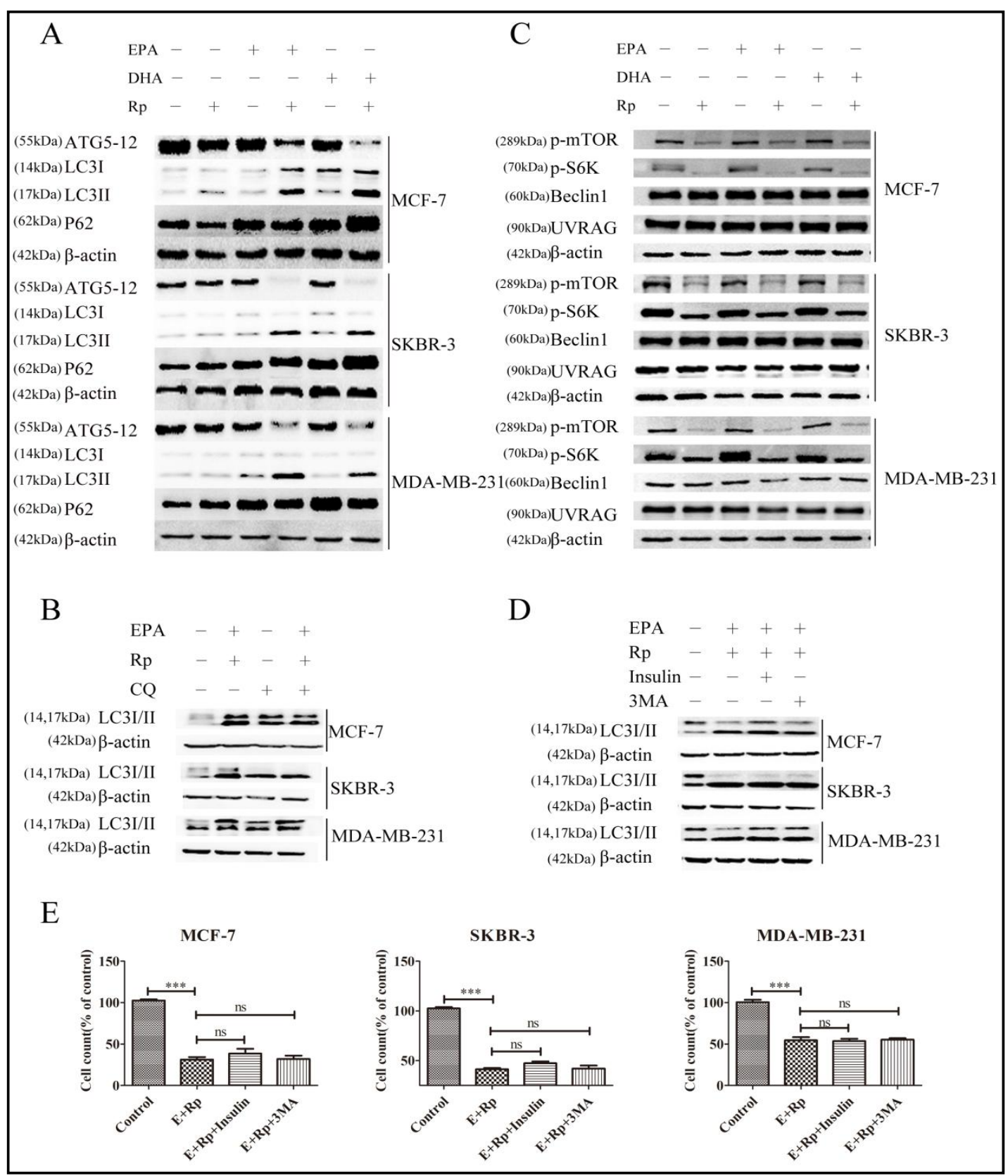

Fig. 3. Autophagy signaling pathway. MCF7, SKBR-3, and MDA-MB-231 cells were treated with $40 \mu \mathrm{M} \omega-3$ PUFAs and $10 \mu \mathrm{M}$ Rp alone or in combination for $48 \mathrm{~h}$. Cell extracts were prepared and subjected to western blot analysis (A). Cells were treated with Rp $(10 \mu \mathrm{M})+$ EPA $(40 \mu \mathrm{M})$ with or without CQ $(5 \mu \mathrm{M})$ for $48 \mathrm{~h}$. Cell extracts were prepared and subjected to western blot analysis (B). Cells were treated with $40 \mu \mathrm{M} \omega-3$ PUFAs and $10 \mu \mathrm{M} \mathrm{Rp}$ alone or in combination for $48 \mathrm{~h}$. Cell extracts were prepared and subjected to western blot analysis (C). Cells were pretreated with $5 \mathrm{mM} 3 \mathrm{MA}$ or $2 \mu \mathrm{M}$ for $1 \mathrm{~h}$ and then exposed to $40 \mu \mathrm{M}$ EPA and 10 $\mu \mathrm{M}$ Rp for $48 \mathrm{~h}$. Cell extracts were prepared and subjected to western blot analysis (D). Results of the cell counting assays (E). Data are represented as the mean $\pm \mathrm{SEM} ;{ }^{*} \mathrm{p}<0.05,{ }^{* *} \mathrm{p}<0.01$, and ${ }^{* * *} \mathrm{p}<0.001$.

determining autophagic flux are described in detail elsewhere [34, 35]. The results showed that the addition of $\omega-3$ PUFAs significantly prevented p62 degradation, and there were no obvious differences in cellular LC3II/ $\beta$-actin levels between cells treated with $\mathrm{Rp}+\omega-3$ PUFAs+CQ and those treated with Rp+ $\omega-3$ PUFAs (Fig. 3A, B), indicating that combination treatment with $\mathrm{Rp}$ and $\omega-3$ PUFAs blocked autophagic flux. Autophagy is tightly controlled 


\section{Cellular Physiology Cell Physiol Biochem 2018;48:2318-2336 \\ and Biochemistry Published online: 15 August, 2018 \begin{tabular}{l|l} 
DOI: 10.1159/000492648 & $\begin{array}{l}\text { (c) } 2018 \text { The Author(s). Published by S. Karger AG, Basel } \\
\text { www.karger.com/cpb }\end{array}$
\end{tabular} \\ Zhu et al.: $\omega$-3 PUFAs and Rapamycin Co-Treatment Induces Synergistic Antitumor}

Effect

by multiple signaling pathways including the mTOR and Beclin-1 pathways [36, 37]. Because mTOR is a negative regulator of autophagy, its activation leads to suppression of autophagic vesicle formation. mTOR phosphorylation at S2448 and p70S6 kinase phosphorylation at T389, which are inhibited by Rp, are widely used as markers of mTOR activity [38]. Western blot analyses of the mTOR kinase substrate, p70S6 kinase, and p-mTOR were

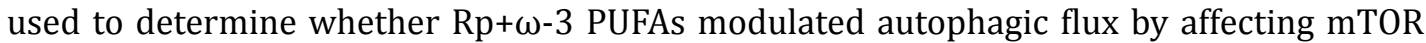
activity. Rp significantly inhibited the levels of p-mTOR and p-S6K, whereas no significant differences were found between the single Rp-treated and combination-treated groups (Fig. 3C). Recent studies have established that insulin induces p70S6 kinase phosphorylation by activating mTOR $[39,40]$. Therefore, we used insulin as an mTOR activator to determine

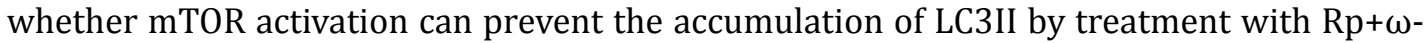
3PUFAs. The results revealed that the addition of insulin had no significant effect on signal transduction or cell death (Fig. 3D, E). The second major protein complex that controls autophagic activity is Beclin-1. No significant differences in the concentrations of Beclin-1 and UVRAG were observed between the cancer cell treatment groups (Fig. 3C). Furthermore, we determined that 3-MA, which is widely used as a class III phosphatidylinositol 3-kinase

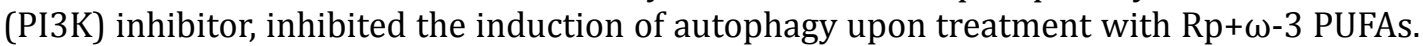
Consistent with the results shown in Fig. 3C, there were no significant differences between cells treated with or without 3-MA (Fig. 3D, E). These results demonstrate that $\mathrm{Rp}+\omega$-3PUFAs modulate autophagic flux independently of mTOR and Beclin-1 complexes.

\section{$\omega$-3 PUFA enhances Rp-induced ROS production}

$\omega-3$ PUFAs are highly active molecules, and recent studies have suggested that ROS and lipid peroxidation play crucial roles in their anticancer activity [41, 42]. Furthermore, studies have shown that ROS production in cancer cells is one of the mechanisms underlying the synergetic cytotoxicity observed in cases of combination anti-tumor treatments [43, 44]. Therefore, we determined whether ROS generation plays a role in the combined cytotoxic effects of Rp and $\omega-3$ PUFAs. Both Rp and $\omega-3$ PUFAs alone led to slightly higher ROS production than the control as assessed by the levels of DCF, whereas the co-treatment of cells with Rp and $\omega-3$ PUFAs resulted in a significant increase in ROS levels compared to Rp or $\omega$-3 PUFA treatments alone (Fig. 4A). As expected, the enhanced DCF signal (ROS level) and cell death were significantly blocked when cells were pre-treated with the ROS scavenger NAC (Fig. 4B, C). These results indicate that the synergistic effects of combination treatment with $\mathrm{Rp}$ and $\omega-3$ PUFA on cell death were modulated through ROS production. To determine whether supplementation with fatty acids other than $\omega-3$ PUFAs exhibited the same effects on ROS production, we evaluated the effects of palmitic acid (PA) and oleic acid $(\mathrm{OA})$ as representatives of saturated and monounsaturated fatty acids, respectively. The results showed that neither OA nor PA treatment alone or combined with Rp influenced ROS production in all breast cancer cell types (Fig. 4D), suggesting that $\omega$-3 PUFAs enhanced Rpinduced ROS production because of their unique fatty acid structure.

Combination treatmentwith Rpand $\omega-3$ PUFA inhibits glycolysis and glutamine metabolism

Metabolic reprogramming is a hallmark of cancer and has been an area of accelerated research during the last decade [45]. A classical metabolic change in cancer cells is the increased consumption of glucose and glutamine [46, 47]. Numerous studies have demonstrated that the mTOR complex as an energy sensor plays a key role in modulating cancer metabolism. In addition, a recent study reported that $\omega$-3 PUFAs as both a source of fuel but also as a bioactive component participate in cancer metabolism [48, 49]. We determined whether the combination treatment of $\omega-3$ PUFA+Rp treatment induced a shift in cancer metabolism. The significantly decreased expression of key enzymes in glycolysis (hexokinase 2, pyruvate kinase isozyme M2, phosphofructokinase, platelet, and PD, the pentose phosphate pathway, and glutaminase were detected using immunoblotting after in vitro combination treatment (Fig. 5B, C); however, the rate of glucose uptake did not change in each group (Fig. 5A, B). Moreover, basal ECAR significantly decreased in the cases of Rp 


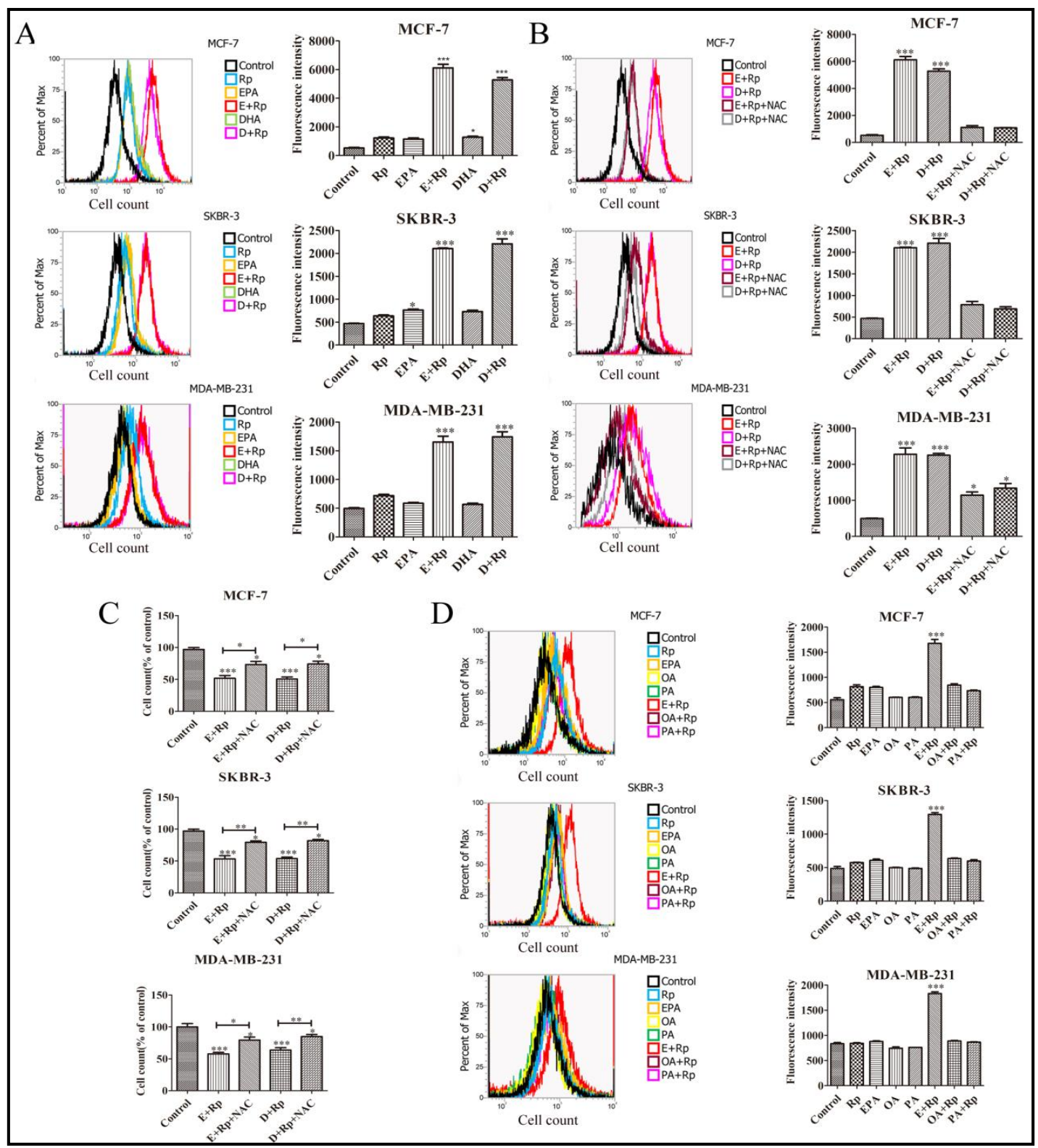

Fig. 4. ROS production. (A, B, and C) ROS generation was measured in MCF7, SKBR-3, and MDA-MB-231 cells by staining with DCFH-DA. Cells were treated with $40 \mu \mathrm{M} \omega-3$ PUFAs and $10 \mu \mathrm{M}$ Rp alone or in combination for $4 \mathrm{~h}(\mathrm{~A})$. Cells were pretreated with $5 \mathrm{mM}$ NAC for $1 \mathrm{~h}$ and then exposed to $40 \mu \mathrm{M} \omega$-3 PUFAs and $10 \mu \mathrm{M}$ Rp for $4 \mathrm{~h}$ (B). Cells were pretreated with $5 \mathrm{mM}$ NAC for $1 \mathrm{~h}$ and then exposed to $40 \mu \mathrm{M} \omega$-3 PUFAs and $10 \mu \mathrm{M}$ $\mathrm{Rp}$ for $48 \mathrm{~h}$, followed by the cell counting assay (C). Cells were treated with $40 \mu \mathrm{M}$ fatty acid and $10 \mu \mathrm{M} \mathrm{Rp}$ alone or in combination for $4 \mathrm{~h}(\mathrm{D})$. Values represent the mean $\pm \operatorname{SEM}(\mathrm{n}=3) ;{ }^{*} \mathrm{P}<0.05 ;{ }^{* *} \mathrm{P}<0.01 ;{ }^{* * *} \mathrm{P}<0.001$.

treatment alone and the combination treatment (Fig. 5D). We further investigated the change in metabolic intermediates through GC-MS, and found that the key metabolites of glycolysis and glutamine metabolism such as lactic acid and glutamic acid were significantly reduced with $\mathrm{Rp}$ treatment alone and the combination treatment (Fig. 5E). These results indicate that $\omega-3$ PUFAs and Rp may participate in different metabolic pathways and that Rp is more powerful in the regulation of glucose and glutamine metabolism. 


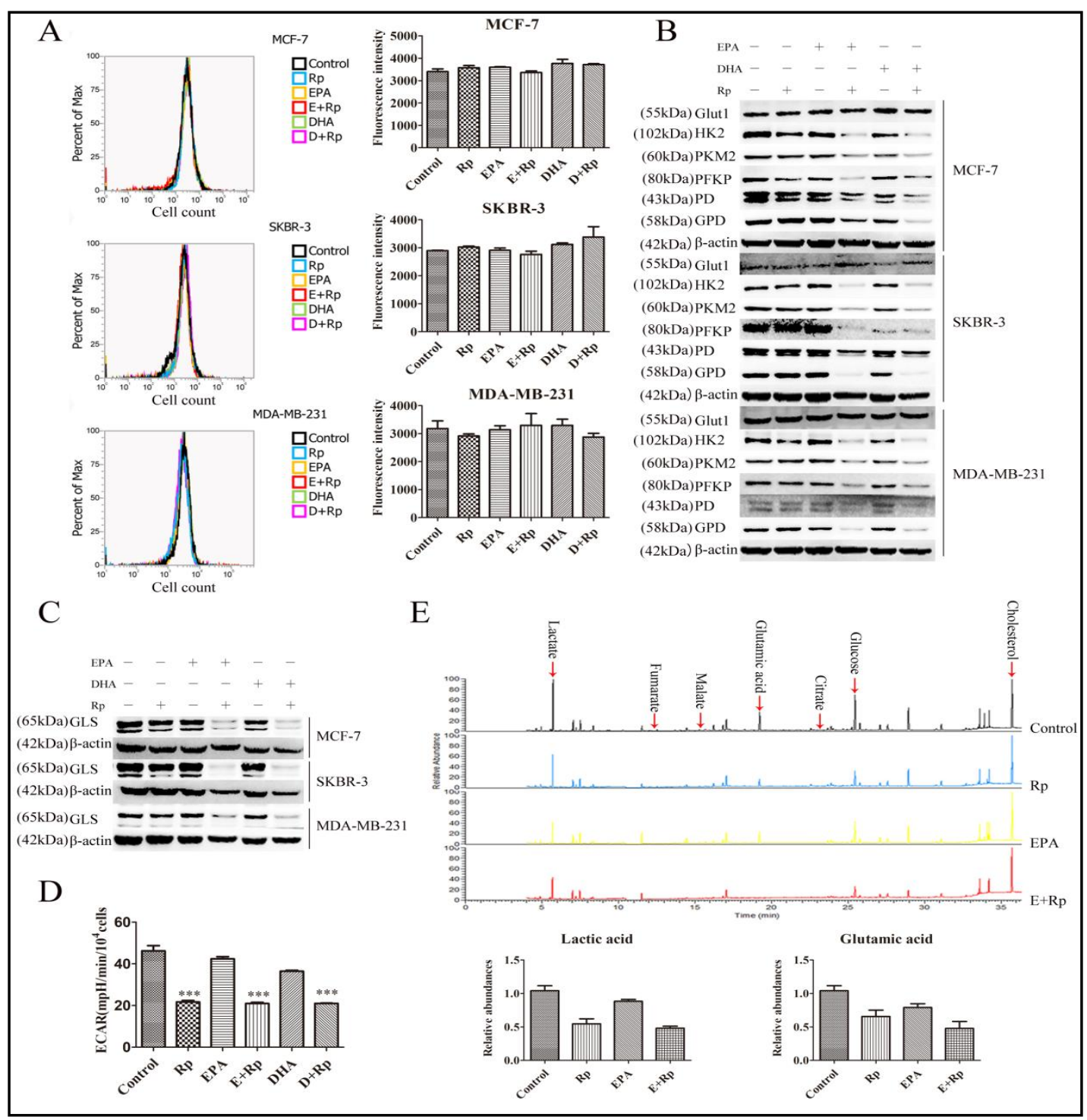

Fig. 5. Glycolysis and glutamine metabolism. MCF7, SKBR-3, and MDA-MB-231 cells were treated with 40 $\mu \mathrm{M} \omega$-3 PUFAs and $10 \mu \mathrm{M}$ Rp. Glucose uptake was analyzed by flow cytometry with 2-NBDG (A) Cells were treated with $40 \mu \mathrm{M} \omega-3$ PUFAs and $10 \mu \mathrm{M}$ Rp for $48 \mathrm{~h}$, after which cell extracts were prepared and subjected to western blot analysis (B-C). Cells were treated with $40 \mu \mathrm{M} \omega-3$ PUFAs and $10 \mu \mathrm{M}$ Rp for $6 \mathrm{~h}$, and then the ECAR was determined using the Seahorse XF24 Extracellular Flux Analyzer (D). Metabolic intermediates were measured by GC-MS (mean \pm SEM in duplicate) (E).

\section{Combination treatment increases $\beta$-oxidation and oxidative phosphorylation}

The combination treatment induced a significant change in fatty acid metabolism and oxidative phosphorylation. Fatty acid metabolism significantly decreased, whereas catabolism increased. The key enzymes involved in $\beta$-oxidation and oxidative phosphorylation clearly increased due to the addition of Rp and $\omega$-3 PUFAs (Fig. 6A, B), suggesting that the combination treatment of $\mathrm{Rp}$ and $\omega-3$ PUFAs induces significant metabolic shifts. To further verify the metabolic change, basal OCR and key intermediate metabolites were measured. We found that the basal OCR and metabolites involved in $\beta$-oxidation and oxidative phosphorylation (malate, fumarate, and citrate) significantly increased with $\omega-3$ PUFA treatment and the combination treatment (Fig. 6C, D). Numerous studies have demonstrated that fatty acid oxidation is required for the increased ROS levels [50]. Furthermore, it has been suggested 

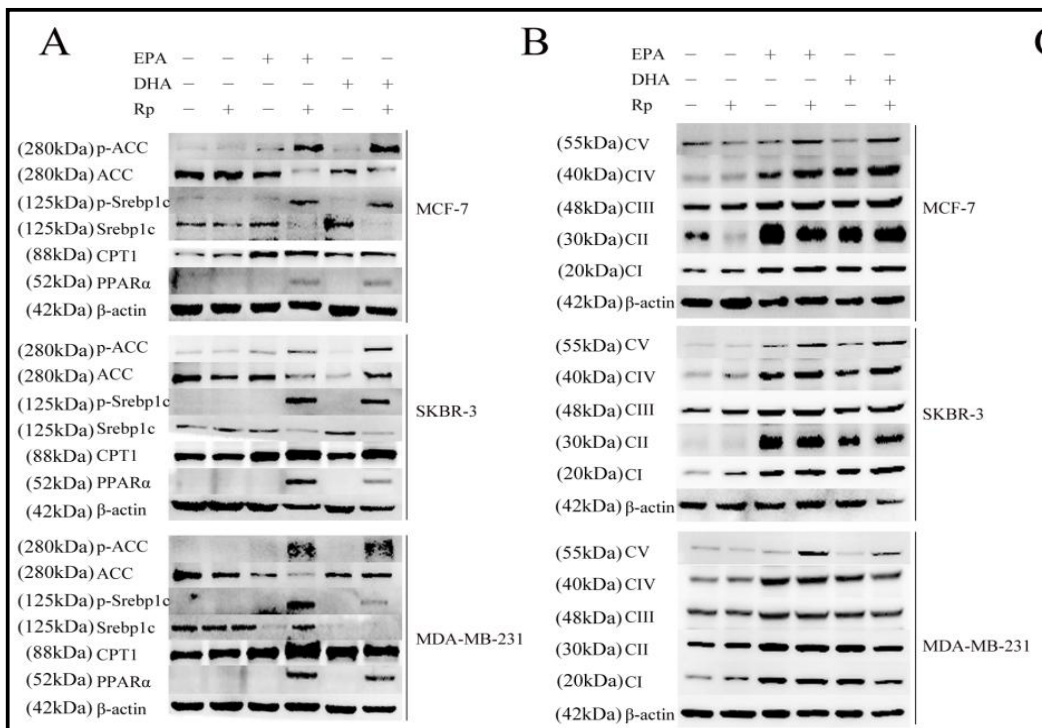

$\mathrm{C}$

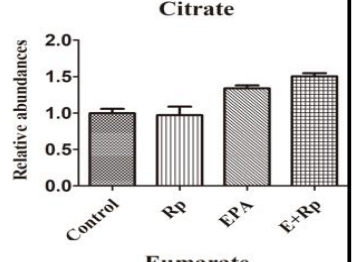

Fumarate

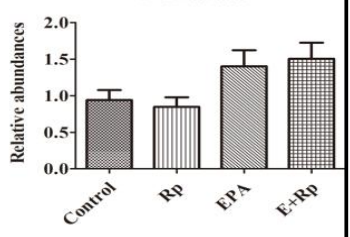

Malate

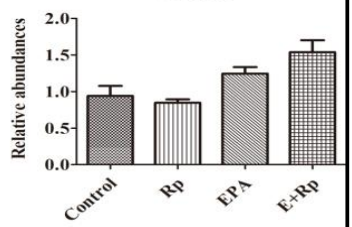

MCF-7

F
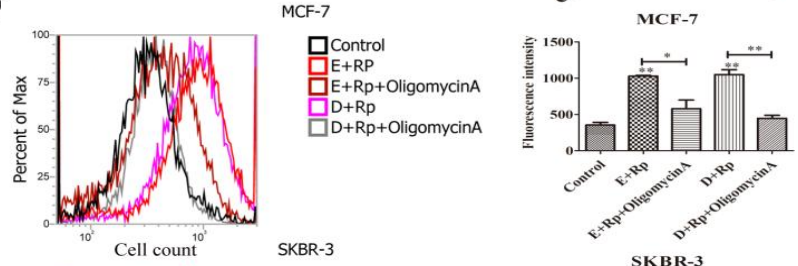

Control

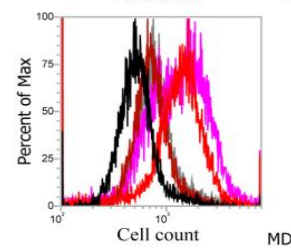

E+Rp

E+Rp+OligomycinA

D $+R p$

$\square$ D+Rp+OligomycinA

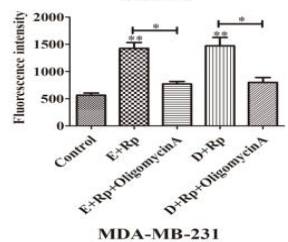

MDA-MB-231

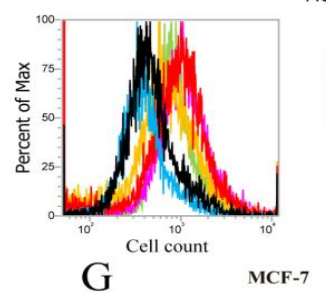

口Control

E $\mathrm{E}+\mathrm{Rp}$

CPT1KD-

$\square$ CPT1KD-D+Rp

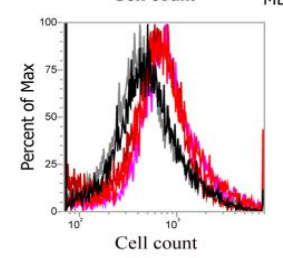

Control

E+Rp

$\square$ D+Rp

$\square$ D+Rp+OligomycinA

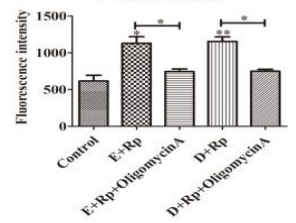

SKBR-3

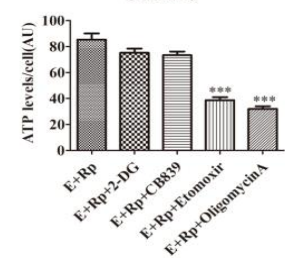

MDA-MB-231
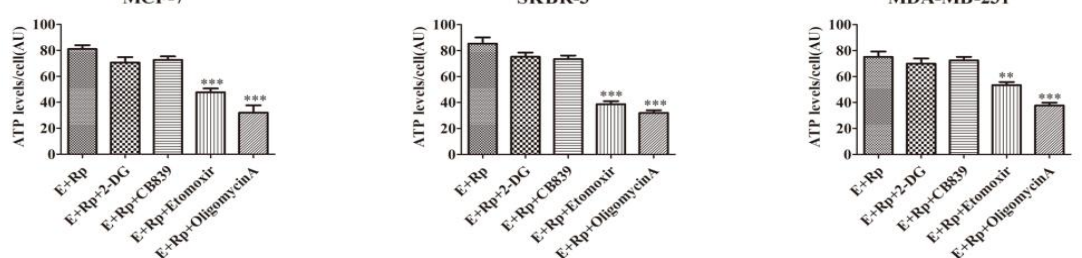

Fig. 6. $\beta$-oxidation and oxidative phosphorylation. MCF7, SKBR-3, and MDA-MB-231 cells were treated with $40 \mu \mathrm{M} \omega-3$ PUFAs and $10 \mu \mathrm{M}$ Rp for $48 \mathrm{~h}$, after which the cell extracts were prepared and subjected to western blot analysis (A-B). Metabolic intermediates were measures by GC-MS (mean \pm SEM in duplicate) (C). Cells were treated with $40 \mu \mathrm{M} \omega-3$ PUFAs and $10 \mu \mathrm{M} \mathrm{Rp}$ for $6 \mathrm{~h}$ and then the OCR was determined using the Seahorse XF24 Extracellular Flux Analyzer (D). Cells were treated with $40 \mu \mathrm{M} \omega-3$ PUFAs and $10 \mu \mathrm{M}$ Rp with or without CPT1-knockdown for $4 \mathrm{~h}$ and ROS generation was measured in MCF7, SKBR-3, and MDAMB-231 cells by staining with DCFH-DA (E). Cells were treated with $40 \mu \mathrm{M} \omega-3$ PUFAs and $10 \mu \mathrm{M}$ Rp with or without Oligomycin A for $4 \mathrm{~h}$, and ROS generation was measured in MCF7, SKBR-3, and MDA-MB-231 cells by staining with DCFH-DA (F). ATP was measured by a commercial kit after combination treatment with or without various inhibitors $(\mathrm{G})$. 


\section{Cellular Physiology Cell Physiol Biochem 2018;48:2318-2336 \begin{tabular}{ll|l} 
DOI: 10.1159/000492648 & $\begin{array}{l}\text { O } 2018 \text { The Author(s). Published by S. Karger AG, Basel } \\
\text { www.karger.com/cpb }\end{array}$
\end{tabular} \\ Zhu et al.: $\omega$-3 PUFAs and Rapamycin Co-Treatment Induces Synergistic Antitumor Effect}

that $\omega-3$ PUFAs have a considerably high affinity to PPAR $\alpha$ and that $\omega-3$ PUFA binding induces a conformational change in the nuclear receptors, triggering the transcription of specific genes including these encoding for various metabolic and cellular processes such as fatty acid oxidation [51]. Thus, we presumed that combination treatment-induced ROS production may be caused by fatty acid $\beta$-oxidation and oxidative phosphorylation. To confirm this hypothesis, we determined that ROS production induced by combination treatment was impaired after CPT1 knockdown or oligomycin A addition (Fig. 6E, F). These results further demonstrated that $\beta$-oxidation and oxidative phosphorylation were the main sources of ROS induced by $\omega-3$ PUFAs and Rp. Next, to test whether combinationinduced metabolic shifts were associated with a change in mitochondrial ATP production, we analyzed ATP levels after the addition of 2-DG (an inhibitor of glycolysis), CB839 (an inhibitor of glutaminase), etomoxir (an inhibitor of fatty acid oxidation), and oligomycin A (an inhibitor of fatty acid oxidation). As shown in Fig. 6G, ATP levels in the combinationtreated cells were almost insensitive to 2-DG and CB839 treatment. In contrast, inhibition of oxidative phosphorylation and $\beta$-oxidation by oligomycin A and etomoxir showed that ATP levels were more dependent on mitochondria. These results further demonstrated that the combination treatment changed the energy consumption and production of cancer cells.

\section{Combination treatment suppresses tumor growth in xenograft models}

To evaluate the anticancer efficacy of the combination treatment on breast cancer in vivo, we used MDA-MB-231 cancer cell xenografts in athymic nu/nu mice as representatives of the in vivo model. Neither Rp nor EPA significantly inhibited tumor growth when administered alone compared with the control group (Fig. 7A). However, the combination treatment caused a significant reduction in tumor growth in a time-dependent manner. At the end of the treatment period, the average tumor volumes in the combination treatment groups were significantly smaller than those in the other groups (Fig. 7A). Moreover, the tumor mass showed the same trend (Fig. 7B). A number of studies have confirmed that Ki67 protein expression is a strong indicator of patient outcome [52]; therefore, we determined the Ki67 expression in each group. Tumor tissues were collected, and Ki67 expression was assessed using immunohistochemistry (IHC). A significant decrease in Ki67 expression was observed following treatment with Rp+EPA compared with EPA and Rp treatment alone (Fig. 7C, D). Clinical investigations have shown that metabolic abnormalities consistently occurred in patients during treatment with $\mathrm{Rp}[9,53]$. To determine whether EPA supplementation improved Rp-induced metabolic disorders, serum biochemical indexes were measured, including serum levels of TG, TC, HDL-C, and LDL-C. EPA completely reversed Rp-induced hypercholesterolemia and hypertriglyceridemia (Fig. 7E). To determine whether the cell death mechanism observed in vitro could also be detected in the xenograft model, the key proteins in tumor tissues were analyzed. The in vivo data strongly supported the in vitro data; treatment with Rp+EPA significantly increased the key enzymes of $\beta$-oxidation and oxidative phosphorylation, whereas the enzymes of glycolysis and glutamine metabolism were significantly reduced in mice that received this combination treatment (Fig. 7F). Furthermore, we detected the level of MDA (one of the main oxidation products) and found that the combination treatment dramatically increased MDA production (Fig. 7G), in accordance with our in vitro results. These data support the proposed therapeutic mechanism of $\omega$-3 PUFA-supplemented Rp treatment.

\section{Combination treatment suppresses tumorigenesis in the MMTV-PYVT breast cancer mouse} model

The xenograft model has been shown to be inaccurate for predicting the clinical outcomes of novel drugs, because the mice used in experiments are immune-deficient and the tumor is not in situ. To evaluate anti-tumor activity, we used the transgenic strain FVB/N$\mathrm{Tg}$ (MMTV-PyVT)634Mul/J (also known as PyVT) in this study as a novel in vivo model of highly aggressive breast cancer [54]. We also investigated whether the ROS scavenger NAC impeded the anti-tumor effects of the combination treatment in vivo. After euthanization, 


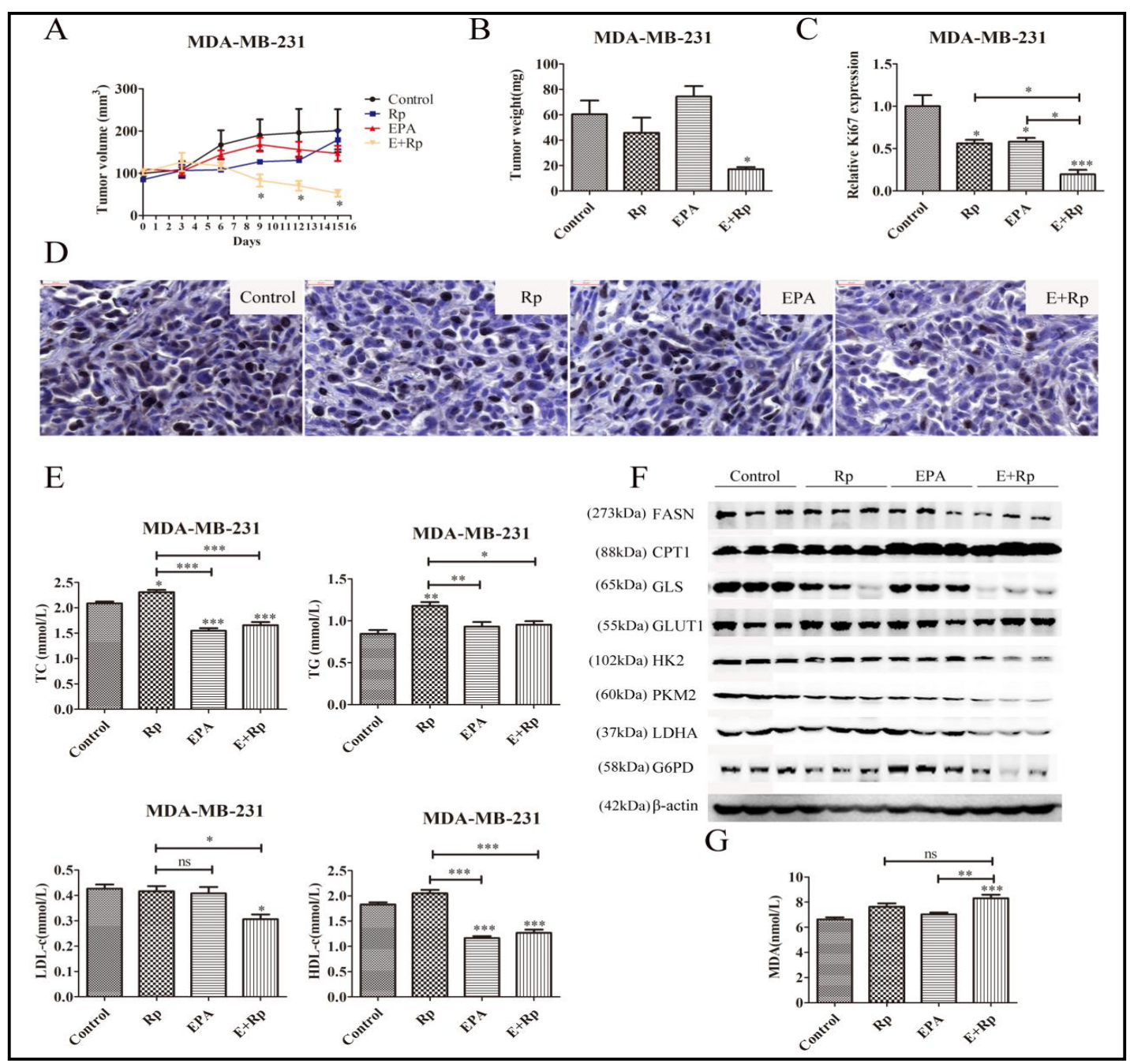

Fig. 7. Anti-tumor effects in xenograft model. Effects of $\omega-3$ PUFA and Rp treatment on tumor growth in a xenograft model. Tumors were measured at the indicated time points ( $n=10$ per group) (A). Tumor weight in each group (B). Representative images of IHC staining of Ki67 and Ki67-positive cell numbers. The results represent the mean percentage of Ki67-positive cells relative to that of the control (C-D). TG, TC, HDL-C, and LDL-C levels were determined by a programmable automatic biochemical analyzer according to the manufacturer's instructions (E). Western blot analysis of xenograft models treated with Rp and EPA alone or in combination (F). MDA levels were determined by a commercial kit according to the manufacturer's instructions $(G)$.

the weight of tumors in the combination-treated mice was significantly lower than that in the other groups of PyVT mice (Fig. 8A). Moreover, Ki67 expression was in accordance with tumor weight (Fig. 8B, C), and Rp-induced hypertriglyceridemia and hypercholesterolemia were completely reversed by $\omega-3$ PUFA supplementation (Fig. 8D). We also observed that MDA levels dramatically increased in combination-treated mice (Fig. 8E). Addition of the ROS scavenger NAC significantly reduced the anti-tumor efficacy of Rp+EPA (Fig. 8A-C). These results further demonstrated the possible mechanism of the combination treatment. Because Rp and $\omega$-3 PUFAs are safe to use in clinical applications, we did not investigate the toxicity of the combination treatment in our experiment, but measured the change in body weight and conducted a liver biopsy in each group. We did not find any significant change in the body weight or in the liver biopsy (Fig. 8F, G), suggesting that the combination treatment was a safe and effective anti-tumor strategy.

\section{KARGER}




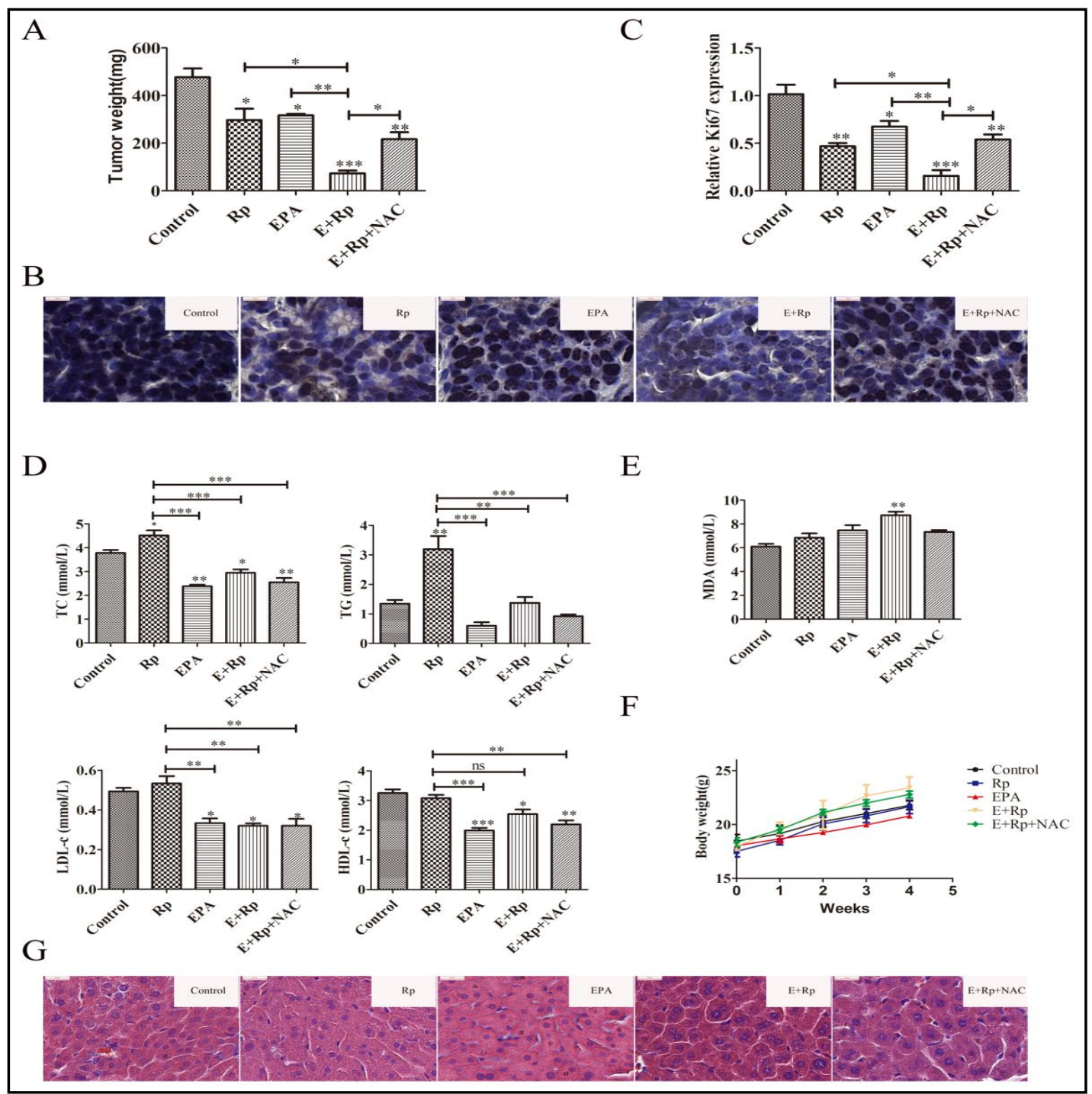

Fig. 8. Anti-tumor effects in the MMTV-PyVT breast cancer mouse model. Tumor weight in each group ( $n=6$ per group) (A). Representative images of IHC staining of Ki67 and Ki67-positive cell numbers. The results represent the mean percentage of Ki67-positive cells relative to that of the control (B-C). TG, TC, HDL-C, and LDL-C levels were determined by a programmable automatic biochemical analyzer according to the manufacturer's instructions (D). MDA levels were determined by a commercial kit according to the manufacturer's instructions (E). Effects of $\omega-3$ PUFA and Rp treatments on body weight (F). Representative images of hematoxylin and eosin staining of mice liver in each group $(G)$.

\section{Discussion}

PI3K/Akt/mTOR pathway inhibitors used most commonly in clinical applications target a more distal pathway component, the mTOR. Rp, the prototypic mTOR inhibitor, was discovered in 1975 as a potent anti-fungicide, and its ability to inhibit the proliferation of cancer cell lines was shown more than 20 years ago [4,5]. However, a major obstacle in the use of the Rp therapy in breast cancer is the occurrence of drug resistance and dyslipidemia $[7,9]$. Clear evidence has linked metabolic disorders to a high risk of incidence as well as poor clinical outcomes of breast cancer. Furthermore, changes in the levels of adipokines caused by obesity are associated with the initiation and progression of breast cancer. Therefore, Rp

\section{KARGER}




\section{Cellular Physiology Cell Physiol Biochem 2018;48:2318-2336 \begin{tabular}{l|l|l} 
and Biochemistry $10.1159 / 000492648$ & $\begin{array}{l}\text { DO } 2018 \text { The Author(s). Published by S. Karger AG, Basel } \\
\text { www.karger.com/cpb }\end{array}$
\end{tabular} Zhu et al.: $\omega$-3 PUFAs and Rapamycin Co-Treatment Induces Synergistic Antitumor}

Effect

and its analogs have been studied in combination with various lipidor cholesterol-lowering drugs, and exhibit considerably powerful anti-tumor effects [12, 13]. In this study, synergy was observed with $\mathrm{Rp}$ and $\omega-3$ PUFAs; the combination of $\mathrm{Rp}$ and $\omega-3$ PUFAs enhanced the level of apoptosis compared to that with treatment of either drug alone. Furthermore, supplementation with $\omega-3$ PUFAs significantly reduced Rpinduced hypertriglyceridemia and hypercholesterolemia. Interestingly, $\omega-3$ PUFAs sensitized tumor cells to Rp-induced apoptosis while blocking Rp-induced autophagy activation. Increasing

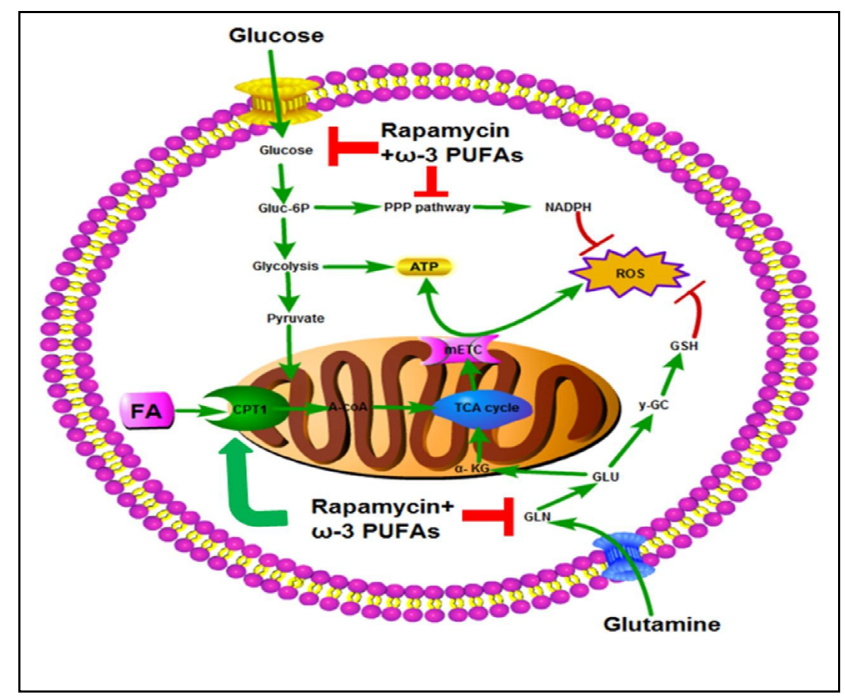

Fig. 9. Alterations of metabolic pathways caused by $\mathrm{Rp}$ and $\omega$-3 PUFA treatment. evidence points to the fact that autophagy allows cancer cells to continue to survive by recycling intracellular components and persisting under low-nutrient or stress-induced conditions [29]. Therefore, disruption of autophagic flux may be the main reason underlying improved drug resistance.

Previous research has demonstrated that Rp combined with an ROS inducer EF24 significantly induces cancer cell death via ROS production [55]. Because $\omega-3$ PUFAs are highly active molecules, we presumed that the synergistic effect of Rp combined with $\omega-3$ PUFAs is related to ROS production, which can directly cause cytotoxicity or influence intracellular signaling pathways, resulting in growth inhibition or death of tumor cells. The results showed that the synergistic effects of the $\omega-3$ PUFA+Rp combination on cell death were caused by ROS production, which may have been related to the degree of unsaturation.

Intracellular ROS is mainly generated through various metabolic pathways $[56,57]$. Numerous published studies have demonstrated that mTOR senses the energy supply, nutrients, growth factors, and other conditions in the tumor microenvironment, and that TORC1 complex activity is necessary for appropriate glycolysis, glutamine consumption, the pentose-phosphate pathway, and lipid and nucleotide synthesis [48]. Moreover, $\omega$-3 PUFAs not only as a source of fuel but also as bioactive components participate in cancer metabolism [49]. Therefore, we postulated that combination treatment-induced ROS production may be attributed to metabolic alterations. Multiple classical methods (e.g., western blotting, seahorse experiments, ATP production, metabonomics) have demonstrated that combination treatment-induced ROS was indeed a result of fatty acid oxidation. Furthermore, combination treatment significantly inhibited glycolysis and glutamine metabolism, which are required for the proliferation and survival of cancer cells. In addition, Rp and $\omega-3$ PUFAs played different roles in metabolism regulation. The inhibition of glycolysis and glutamine metabolism was mainly dependent on Rp treatment, while the increase in $\beta$-oxidation and oxidative phosphorylation was mainly due to the addition of $\omega$-3 PUFAs. After Rp treatment, the metabolism of glucose and glutamine was blocked, and cancer cells had no choice but to use the exogenous fatty acids ( $\omega-3$ PUFAs) for ATP production (Fig. 9). However, the generous utilization of $\omega-3$ PUFAs resulted in ROS production, which led to cell death. Therefore, it might be better for breast cancer patients to be pre-treated with Rp before being administered $\omega-3$ PUFAs. 


\section{Cellular Physiology Cell Physiol Biochem 2018;48:2318-2336

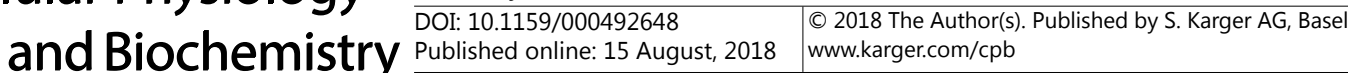 Zhu et al.: $\omega$-3 PUFAs and Rapamycin Co-Treatment Induces Synergistic Antitumor Effect}

\section{Conclusion}

This study proposes the novel combination of Rp and $\omega-3$ PUFAs for the prevention of breast cancer. This combination demonstrated low toxicity and strong therapeutic effects.

\section{Acknowledgements}

This research was supported by the National Key Research and Development Program of China (Grant No. 2017YFD0400200), the National Natural Science Foundation of China (Grant Nos. 31471128 [YQ.C], 31771539 [YQ.C], and 31471321 [Z.H.]), and the YoungThousand-talents Plan (Z.H.). Shenglong Zhu, Zhao He, and Yong Q. Chen conceived and designed the experiments; Shenglong Zhu, Ninghan Feng, Yuelin Tong, Xuan Jiang, Qin Yang, Shunhe Wang, and Guangxiao Lin performed the experiments; Shenglong Zhu, Guangxiao Lin, Wei Chen, and Zhao He analyzed the results; and Shenglong Zhu wrote the manuscript.

\section{Disclosure Statement}

The authors declare that they have no competing interests.

\section{References}

1 De Marchi T, Foekens JA, Umar A, Martens JW: Endocrine therapy resistance in estrogen receptor (ER)positive breast cancer. Drug Discov Today 2016;21:1181-1188.

2 Collignon J, Lousberg L, Schroeder H, Jerusalem G: Triple-negative breast cancer: treatment challenges and solutions. Breast Cancer (Dove Med Press) 2016;8:93-107.

-3 Zhu S, Lin G, Song C, Wu Y, Feng N, Chen W, He Z, Chen YQ: RA and omega-3 PUFA co-treatment activates autophagy in cancer cells. Oncotarget 2017;8:109135-109150.

4 Martin LA, Andre F, Campone M, Bachelot T, Jerusalem G: mTOR inhibitors in advanced breast cancer: ready for prime time? Cancer Treat Rev 2013;39:742-752.

5 Owonikoko TK: Inhibitors of mTOR pathway for cancer therapy, moving on from rapalogs to TORKinibs. Cancer 2015;121:3390-3392.

6 Tian X, Dai S, Sun J, Jiang S, Sui C, Meng F, Li Y, Fu L, Jiang T, Wang Y, Su J, Jiang Y: Inhibition of MDM2 Re-Sensitizes Rapamycin Resistant Renal Cancer Cells via the Activation of p53. Cell Physiol Biochem 2016;39:2088-2098.

-7 Yoon SO, Roux PP: Rapamycin resistance: mTORC1 substrates hold some of the answers. Curr Biol 2013;23:R880-883.

8 Mi W, Ye Q, Liu S, She QB: AKT inhibition overcomes rapamycin resistance by enhancing the repressive function of PRAS40 on mTORC1/4E-BP1 axis. Oncotarget 2015;6:13962-13977.

-9 Murgia MG, Jordan S, Kahan BD: The side effect profile of sirolimus: a phase I study in quiescent cyclosporine-prednisone-treated renal transplant patients. Kidney Int 1996;49:209-216.

10 Bitzur R, Brenner R, Maor E, Antebi M, Ziv-Baran T, Segev S, Sidi Y, Kivity S: Metabolic syndrome, obesity, and the risk of cancer development. Eur J Intern Med 2016; DOI:10.1016/j.ejim.2016.08.019.

11 Cowey S, Hardy RW: The metabolic syndrome: A high-risk state for cancer? Am J Pathol 2006;169:15051522.

12 Taveira-DaSilva AM, Jones AM, Julien-Williams PA, Stylianou M, Moss J: Retrospective review of combined sirolimus and simvastatin therapy in lymphangioleiomyomatosis. Chest 2015;147:180-187.

13 Mir O, Poinsignon V, Arnedos M, Delaloge S, Paci A: Pharmacokinetic interaction involving fenofibrate and everolimus. Ann Oncol 2015;26:248-249.

14 Gan PP, Zhou YY, Zhong MZ, Peng Y, Li L, Li JH: Endoplasmic Reticulum Stress Promotes Autophagy and Apoptosis and Reduces Chemotherapy Resistance in Mutant p53 Lung Cancer Cells. Cell Physiol Biochem 2017;44:133-151. 


\section{Cellular Physiology Cell Physiol Biochem 2018;48:2318-2336 \begin{tabular}{l|l|l} 
and Biochemistry $10.1159 / 000492648$ & $\begin{array}{l}\text { C) } 2018 \text { The Author(s). Published by S. Karger AG, Basel } \\
\text { www.karger.com/cpb }\end{array}$
\end{tabular}

Zhu et al.: $\omega$-3 PUFAs and Rapamycin Co-Treatment Induces Synergistic Antitumor Effect

15 Chen P, Cescon M, Bonaldo P: Autophagy-mediated regulation of macrophages and its applications for cancer. Autophagy 2014;10:192-200.

-16 Zhu S, Jiang X, Jiang S, Lin G, Gong J, Chen W, He Z, Chen YQ: GPR120 is not required for omega-3 PUFAsinduced cell growth inhibition and apoptosis in breast cancer cells. Cell Biol Int 2018;42:180-186.

-17 Kris-Etherton PM, Harris WS, Appel LJ, American Heart Association. Nutrition C: Fish consumption, fish oil, omega-3 fatty acids, and cardiovascular disease. Circulation 2002;106:2747-2757.

18 Mozaffarian D, Lemaitre RN, King IB, Song X, Huang H, Sacks FM, Rimm EB, Wang M, Siscovick DS: Plasma phospholipid long-chain omega-3 fatty acids and total and cause-specific mortality in older adults: a cohort study. Ann Intern Med 2013;158:515-525.

19 Rovito D, Giordano C, Plastina P, Barone I, De Amicis F, Mauro L, Rizza P, Lanzino M, Catalano S, Bonofiglio D, Ando S: Omega-3 DHA- and EPA-dopamine conjugates induce PPARgamma-dependent breast cancer cell death through autophagy and apoptosis. Biochim Biophys Acta 2015;1850:2185-2195.

-20 Zhu S, Ma L, Wu Y, Ye X, Zhang T, Zhang Q Rasoul LM, Liu Y, Guo M, Zhou B, Ren G, Li D: FGF21 treatment ameliorates alcoholic fatty liver through activation of AMPK-SIRT1 pathway. Acta Biochim Biophys Sin (Shanghai) 2014;46:1041-1048.

-21 Shin EA, Sohn EJ, Won G, Choi JU, Jeong M, Kim B, Kim MJ, Kim SH: Upregulation of microRNA135a-3p and death receptor 5 plays a critical role in Tanshinone I sensitized prostate cancer cells to TRAIL induced apoptosis. Oncotarget 2014;5:5624-5636.

22 Leung E, Cairns RA, Chaudary N, Vellanki RN, Kalliomaki T, Moriyama EH, Mujcic H, Wilson BC, Wouters BG, Hill R, Milosevic M: Metabolic targeting of HIF-dependent glycolysis reduces lactate, increases oxygen consumption and enhances response to high-dose single-fraction radiotherapy in hypoxic solid tumors. BMC Cancer 2017;17:418.

-23 Sellick CA, Hansen R, Stephens GM, Goodacre R, Dickson AJ: Metabolite extraction from suspensioncultured mammalian cells for global metabolite profiling. Nat Protoc 2011;6:1241-1249.

-24 Perou CM, Sorlie T, Eisen MB, van de Rijn M, Jeffrey SS, Rees CA, Pollack JR, Ross DT, Johnsen H, Akslen LA, Fluge O, Pergamenschikov A, Williams C, Zhu SX, Lonning PE, Borresen-Dale AL, Brown PO, Botstein D: Molecular portraits of human breast tumours. Nature 2000;406:747-752.

25 Wu G, Fan RS, Li W, Ko TC, Brattain MG: Modulation of cell cycle control by vitamin D3 and its analogue, EB1089, in human breast cancer cells. Oncogene 1997;15:1555-1563.

26 Evan GI, Vousden KH: Proliferation, cell cycle and apoptosis in cancer. Nature 2001;411:342-348.

27 Ilangovan R, Marshall WL, Hua Y, Zhou J: Inhibition of apoptosis by Z-VAD-fmk in SMN-depleted S2 cells. J Biol Chem 2003;278:30993-30999.

28 Green DR, Levine B: To be or not to be? How selective autophagy and cell death govern cell fate. Cell 2014;157:65-75.

29 Alayev A, Berger SM, Kramer MY, Schwartz NS, Holz MK: The combination of rapamycin and resveratrol blocks autophagy and induces apoptosis in breast cancer cells. J Cell Biochem 2015;116:450-457.

30 Yao Q, Fu T, Wang LU, Lai Y, Wang Y, Xu C, Huang L, Guo Y: Role of autophagy in the omega-3 long chain polyunsaturated fatty acid-induced death of lung cancer A549 cells. Oncol Lett 2015;9:2736-2742.

31 Fujita N, Itoh T, Omori H, Fukuda M, Noda T, Yoshimori T: The Atg16L complex specifies the site of LC3 lipidation for membrane biogenesis in autophagy. Mol Biol Cell 2008;19:2092-2100.

-32 Mizushima N, Yoshimori T, Levine B: Methods in mammalian autophagy research. Cell 2010;140:313-326.

-33 Tan KP, Ho MY, Cho HC, Yu J, Hung JT, Yu AL: Fucosylation of LAMP-1 and LAMP-2 by FUT1 correlates with lysosomal positioning and autophagic flux of breast cancer cells. Cell Death Dis 2016;7:e2347.

-34 Zhu S, Wu Y, Ye X, Ma L, Qi J, Yu D, Wei Y, Lin G, Ren G, Li D: FGF21 ameliorates nonalcoholic fatty liver disease by inducing autophagy. Mol Cell Biochem 2016;420:107-119.

-35 Klionsky DJ, Abdelmohsen K, Abe A, Abedin MJ, Abeliovich H, Acevedo Arozena A, Adachi H, Adams CM, Adams PD, Adeli K, Adhihetty PJ, Adler SG, Agam G, Agarwal R, Aghi MK, Agnello M, Agostinis P, Aguilar PV, Aguirre-Ghiso J, Airoldi EM, et al.: Guidelines for the use and interpretation of assays for monitoring autophagy (3rd edition). Autophagy 2016;12:1-222.

-36 Noda T, Ohsumi Y: Tor, a phosphatidylinositol kinase homologue, controls autophagy in yeast. J Biol Chem 1998;273:3963-3966.

37 Xing S, Zhang Y, Li J, Zhang J, Li Y, Dang C, Li C, Fan Y, Yu J, Pei Z, Zeng J: Beclin 1 knockdown inhibits autophagic activation and prevents the secondary neurodegenerative damage in the ipsilateral thalamus following focal cerebral infarction. Autophagy 2012;8:63-76. 


\section{Cellular Physiology Cell Physiol Biochem 2018;48:2318-2336 \begin{tabular}{l|l|l} 
and BOI: 10.1159/000492648 & $\begin{array}{l}\text { () 2018 The Author(s). Published by S. Karger AG, Basel } \\
\text { www.karger.com/cpb }\end{array}$
\end{tabular}

Zhu et al.: $\omega$-3 PUFAs and Rapamycin Co-Treatment Induces Synergistic Antitumor Effect

38 Chiang GG, Abraham RT: Phosphorylation of mammalian target of rapamycin (mTOR) at Ser-2448 is mediated by p70S6 kinase. J Biol Chem 2005;280:25485-25490.

-39 Patti ME, Brambilla E, Luzi L, Landaker EJ, Kahn CR: Bidirectional modulation of insulin action by amino acids. J Clin Invest 1998;101:1519-1529.

40 Kanazawa T, Taneike I, Akaishi R, Yoshizawa F, Furuya N, Fujimura S, Kadowaki M: Amino acids and insulin control autophagic proteolysis through different signaling pathways in relation to mTOR in isolated rat hepatocytes. J Biol Chem 2004;279:8452-8459.

41 Siddiqui RA, Harvey K, Stillwell W: Anticancer properties of oxidation products of docosahexaenoic acid. Chem Phys Lipids 2008;153:47-56.

-42 Trombetta A, Maggiora M, Martinasso G, Cotogni P, Canuto RA, Muzio G: Arachidonic and docosahexaenoic acids reduce the growth of A549 human lung-tumor cells increasing lipid peroxidation and PPARs. Chem Biol Interact 2007;165:239-250.

43 Zou P, Chen M, Ji J, Chen W, Chen X, Ying S, Zhang J, Zhang Z, Liu Z, Yang S, Liang G: Auranofin induces apoptosis by ROS-mediated ER stress and mitochondrial dysfunction and displayed synergistic lethality with piperlongumine in gastric cancer. Oncotarget 2015;6:36505-36521.

44 Zou P, Xia Y, Chen W, Chen X, Ying S, Feng Z, Chen T, Ye Q, Wang Z, Qiu C, Yang S, Liang G: EF24 induces ROSmediated apoptosis via targeting thioredoxin reductase 1 in gastric cancer cells. Oncotarget 2016;7:1805018064.

45 Hanahan D, Weinberg RA: Hallmarks of cancer: the next generation. Cell 2011;144:646-674.

-46 Vander Heiden MG, Cantley LC, Thompson CB: Understanding the Warburg effect: the metabolic requirements of cell proliferation. Science 2009;324:1029-1033.

47 DeBerardinis RJ, Lum JJ, Hatzivassiliou G, Thompson CB: The biology of cancer: metabolic reprogramming fuels cell growth and proliferation. Cell Metab 2008;7:11-20.

-48 Saxton RA, Sabatini DM: mTOR Signaling in Growth, Metabolism, and Disease. Cell 2017;168:960-976.

49 Neschen S, Morino K, Dong J, Wang-Fischer Y, Cline GW, Romanelli AJ, Rossbacher JC, Moore IK, Regittnig W, Munoz DS, Kim JH, Shulman GI: n-3 Fatty acids preserve insulin sensitivity in vivo in a peroxisome proliferator-activated receptor-alpha-dependent manner. Diabetes 2007;56:1034-1041.

-50 Srivastava N, Kollipara RK, Singh DK, Sudderth J, Hu Z, Nguyen H, Wang S, Humphries CG, Carstens R, Huffman KE, DeBerardinis RJ, Kittler R: Inhibition of cancer cell proliferation by PPARgamma is mediated by a metabolic switch that increases reactive oxygen species levels. Cell Metab 2014;20:650-661.

51 Drukala J, Urbanska K, Wilk A, Grabacka M, Wybieralska E, Del Valle L, Madeja Z, Reiss K: ROS accumulation and IGF-IR inhibition contribute to fenofibrate/PPARalpha -mediated inhibition of glioma cell motility in vitro. Mol Cancer 2010;9:159.

-52 Aleskandarany MA, Green AR, Ashankyty I, Elmouna A, Diez-Rodriguez M, Nolan CC, Ellis IO, Rakha EA: Impact of intratumoural heterogeneity on the assessment of Ki67 expression in breast cancer. Breast Cancer Res Treat 2016;158:287-295.

-53 Dutcher JP: Mammalian target of rapamycin (mTOR) Inhibitors. Curr Oncol Rep 2004;6:111-115.

54 Chen Z, Zhang Y, Jia C, Wang Y, Lai P, Zhou X, Wang Y, Song Q Lin J, Ren Z, Gao Q, Zhao Z, Zheng H, Wan Z, Gao T, Zhao A, Dai Y, Bai X: mTORC1/2 targeted by n-3 polyunsaturated fatty acids in the prevention of mammary tumorigenesis and tumor progression. Oncogene 2014;33:4548-4557.

55 Chen W, Zou P, Zhao Z, Chen X, Fan X, Vinothkumar R, Cui R, Wu F, Zhang Q, Liang G, Ji J: Synergistic antitumor activity of rapamycin and EF24 via increasing ROS for the treatment of gastric cancer. Redox Biol 2016;10:78-89.

56 Vaquero EC, Edderkaoui M, Pandol SJ, Gukovsky I, Gukovskaya AS: Reactive oxygen species produced by NAD(P)H oxidase inhibit apoptosis in pancreatic cancer cells. J Biol Chem 2004;279:34643-34654.

-57 Yoshida S, Tsutsumi S, Muhlebach G, Sourbier C, Lee MJ, Lee S, Vartholomaiou E, Tatokoro M, Beebe K, Miyajima N, Mohney RP, Chen Y, Hasumi H, Xu W, Fukushima H, Nakamura K, Koga F, Kihara K, Trepel J, Picard D, et al.: Molecular chaperone TRAP1 regulates a metabolic switch between mitochondrial respiration and aerobic glycolysis. Proc Natl Acad Sci U S A 2013;110:E1604-1612. 